\title{
ISCHEMIC STROKE AND PATENT FORAMEN OVALE
}

\section{Case report}

\author{
Carlos Eduardo Amaral Pereira da Silva', Thiago Cardoso Vale², \\ Flávio José Barbosa Leite3, Thais Gomes Casali², \\ Gustavo de Moraes Ramalho4, Marcelo Maroco Cruzeiro ${ }^{5}$
}

\begin{abstract}
Approximately $40 \%$ of ischemic strokes have no clearly definable etiology and are termed cryptogenic strokes. Patent foramen ovale, a small communication between the left and right atria, is considered to be a risk factor for cerebral embolism. In this study, we report the case of a 29-year-old woman with diagnosis of ischemic stroke due to patent foramen ovale who has undergone percutaneous endovascular closure. The aim of this report is to discuss the relevant aspects of the patent foramen ovale and the cryptogenic stroke, its clinical presentation, diagnosis, management and recurrence.
\end{abstract}

KEY WORDS: interatrial septal abnormalities, paradoxical embolism, ischemic stroke.

\section{Acidente vascular encefálico isquêmico e forame oval patente: relato de caso}

RESUMO - Aproximadamente $40 \%$ dos acidentes vasculares encefálicos isquêmicos não apresentam etiologia definida e são classificados como criptogênicos. O forame oval patente, uma pequena comunicação entre os átrios direito e esquerdo, é considerado um fator de risco para embolismo cerebral. No presente artigo, relatamos o caso de uma jovem de 29 anos com o diagnóstico de acidente vascular encefálico isquêmico decorrente do forame oval patente que foi submetida ao fechamento endovascular percutâneo. $O$ presente relato discute aspectos relevantes da apresentação clínica, diagnóstico, manejo clínico e recorrência desta condição.

PALAVRAS-CHAVE: forame oval patente, embolia paradoxal, acidente vascular encefálico isquêmico.

There are different possible causes of stroke, but approximately $20 \%$ are of cardioembolic origin 1 . If it is not discovered what caused the ischemic event, it is classified as cryptogenic. Strokes of unknown cause are particularly common in young adults, accounting for $10-40 \%$ depending on the population ${ }^{2}$.

We report the case of a young woman presenting stroke associated with patent foramen ovale (PFO) who has undergone percutaneous endovascular closure.

\section{CASE}

A 29-year-old woman was brought to the Emergency Department in August 2004 after a one-day history of weak- ness in the right upper and lower limbs. A non-smoker, who had not taken oral contraceptives for years, the patient did not have any family background of neurological disease, but had an older sister with venous thrombosis. Physical, cardiologic and neurologic examinations in the Emergency Department were normal, except for the right hemiparesis and mild motor dysphasia. A cranial computed tomography without contrast showed focal hypodensity in the putamen of the left hemisphere. She was then submitted to a magnetic resonance imaging (MRI) of the brain (Figure), which showed signs of infarcts in the basal ganglia and corona radiata in the left hemisphere. Carotid and vertebral Doppler scans were normal. Laboratory tests included normal levels of erythrocyte sedimentation rate, antithrombin III activity, protein C and S antigen, plasma homocys-

\footnotetext{
Monte Sinai Hospital, Juiz de Fora (MG), Brazil: 'Lecturer in the Department of Morphology of the Federal University of Juiz de Fora, Responsible for the Service of Vascular and Endovascular Neurosurgery in the Monte Sinai Hospital, Juiz de Fora MG, Brazil (UFJF); ${ }^{2}$ Medical student UFJF; ${ }^{3}$ Neurologist, Chief of the Neurology Service in the Monte Sinai Hospital, Juiz de Fora MG, Brazil; ${ }^{4} \mathrm{MD}$, Cardiologist in the Monte Sinai Hospital, Juiz de Fora MG, Brazil; ${ }^{5}$ Msc in Neurology, Fluminense Federal University (UFF) Niterói RJ, Brazil. Assistant Lecturer in the Department of Morphology UFJF. Neurologist in the Monte Sinai Hospital, Juiz de Fora MG, Brazil.
}

Received 24 November 2005, received in final form 17 April 2006. Accepted 2 June 2006.

Dr. Carlos Eduardo Amaral Pereira da Silva - Avenida Barão do Rio Branco 2370 / 802 - $36010-011$ Juiz de Fora MG - Brasil. E-mail: carloseduardo@neuroclinicajf.com.br 


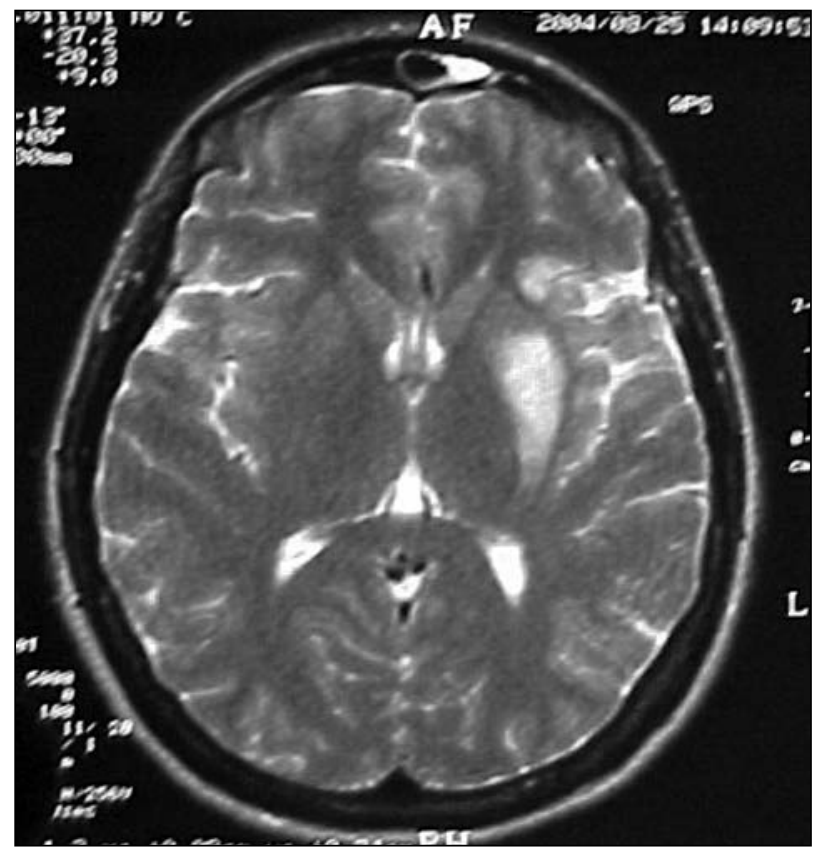

Figure. MRI scan of the brain showing signs of infarcts in the basal ganglia and corona radiata in the left hemisphere.

teine, antiphospholipid antibody panel, determination of antinuclear factor and anti-DNA antibodies, MTHFR gene mutation, VDRL and HIV antibodies search, anti-SSA/RO and anti-SSB/RA antibodies, D-dimer, determination of anticardiolipin antibodies, vitamin B12, lupus anticoagulant, thyroid stimulating hormone, Leiden $\mathrm{V}$ factor study, prothrombin gene mutation, fibrinogen, lipids, activated-protein $C$ resistance and partial thromboplastin time, as well as a normal complete blood count and routine blood chemistries. The contrast-enhanced transesophageal echocardiography showed normal except for the presence of the PFO (diameter $<3 \mathrm{~mm}$ ) and mitral valve prolapse. Further investigation excluded atria septum aneurysm and shunt at rest. Finally, she was submitted to a cerebral arteriography which showed left middle cerebral artery occlusion in its origin.

The patient was informed as to the options of treatment, and she decided to use the long-term therapy of oral anticoagulant. She returned after 9 months with sequelae in the right limbs and was persuaded to undergo percutaneous endovascular closure. The device (Amplatzer PFO occluder) was successfully adopted under continuous monitoring through the transesophageal echocardiography. After percutaneous closure, the patient received clopidogrel (75 mg/day for 1 month) and aspirin (100 mg/day for 6 months). Long-lasting physical therapy was proposed and in a short-term follow-up (18 months), she had neither recurrence nor worsening of symptoms. As a permanent sequelae, the patient had impairment of her fine upper limb coordination.

\section{DISCUSSION}

Some cardiologists estimate that 70,000 to 100,000 strokes per year in the United States are secondary to paradoxical embolism via a $\mathrm{PFO}^{3,4}$. Depending on the criteria used for diagnosis and the technology used in cardiac assessment, the prevalence of PFO in the healthy population is approximately $20-25 \% \%^{3,5-8}$. Thus, detection of a PFO during evaluation of a patient with a stroke is not surprising, and the frequency of PFO detection in these patients can be as high as $40-45 \%{ }^{9}$. This frequency of detection is especially high among people without any other obvious explanation for the stroke. Overell et al. ${ }^{10}$ concluded from a meta-analysis of several studies that the relative risk of stroke compared to non-stroke controls increased by a factor of 1.83 if a PFO was present.

Silva et al. ${ }^{8}$ identified 29 cryptogenic ischemic strokes in their group of patients younger than 55 . Fortyone point three percent of these patients had some form of interatrial septal abnormality. Five had a PFO and seven had PFO plus interatrial septum aneurysm. They concluded that their small series is in accordance with other studies and points to a possible relation between interatrial septal abnormalities and ischemic stroke. However, this relation needs to be confirmed by large studies.

Presumably, most of the neurologic symptoms are secondary to paradoxical embolism of small thrombi that arise in the venous system and pass through the PFO during a transient right-to-left shunt. However, there is normally no direct evidence for paradoxal embolism and systematic screening for deep venous thrombosis in the lower limbs or pelvis has led to extremely variable estimates. Other possible explanations for stroke secondary to PFO, but independent of paradoxical embolism, include secondary cardiac arrhythmias or abnormalities of the endocardial surface of the septum or within the PFO which are a focus for thrombus formation ${ }^{11,12}$. In short, the mechanism of strokes among young people with PFO is ill-defined.

Patients with PFO are usually younger and have a lower incidence of hypertension, hypercholesterolemia, and smoking habits than do people with other causes of strokes ${ }^{3}$. Although PFO can be found in older patients, these people have a high prevalence of atherosclerosis or other cardiac diseases, including atrial fibrillation, which could explain their vascular events. Thus, a PFO might not be perceived as being as important in an older person as in a young adult ${ }^{5,10}$. Fukujima et al. ${ }^{13}$, in their transversal transesophageal echocardiography (TEE) study of 523 patients without any prior evidence of cardiac abnorma- 
lity, concluded that TEE, widely used to diagnose cardiac source of cerebral embolism in young patients, seems to be useful for patients aged over 45 , in whom risk of cerebral embolism is underestimated. Because most people with PFO never have symptoms, some lesions can be assumed to be associated with a greater risk of strokes than others. Establishing a relationship between the size of the septal abnormality, a concomitant atrial septal aneurysm, the presence of a shunt at rest, or the size of the right-to-left shunt might identify those people at greatest risk.

With the use of contrast-enhanced TEE, the PFO is detected frequently during evaluation of patients with an ischemic stroke. The TEE without contrast showed a high sensitivity (90\%) and specificity (93\%) for detecting PFO whereas contrast transthoracic echocardiography has significant limitations for visualizing the atrial septum ${ }^{14-16}$. The use of different contrasts (aerated colloid solution) has increased the sensitivity of echographic techniques for diagnosing shunts through the foramen oval. According to Mesa et al. ${ }^{14}$, a greater mobility of the membrane of the oval cavity and a large degree of shunt contrast, as well as shunt at rest detected by saline-contrasted TEE, seems to identify PFO with ischemic stroke. Negrão et al. ${ }^{17}$ considered the transcranial Doppler as another valuable diagnostic tool to detect abnormalities of interatrial septum.

A right-to-left shunt is considered present if microbubbles are detected within 3 to 5 cardiac cycles ${ }^{18}$. The volume or number of bubbles is frequently used to quantify the size of the shunt. However, correlations between the size of the right-to-left shunt and the risk of stroke are not strong. Schuchlenz et al. ${ }^{19}$ evaluated PFO size in a series of patients who subsequently underwent catheter closure of the defect and found that the balloon diameter of the PFO was considerably larger than the diameter estimated by TEE. They also reported that a PFO diameter greater than $4 \mathrm{~mm}$ was associated with increased thromboembolic risk. De Castro et al. ${ }^{20}$ noted a strong correlation with the risk of embolization when a PFO is associated with a highly mobile septal membrane.

Regardless of the presence of a PFO, the perceived risk of recurrent strokes among patients with symptomatic strokes is so high that some stroke prophylaxis regimen should be prescribed. The choices of antiplatelet aggregating agents, oral anticoagulants, transcatheter placement of an occlusive device or cardiac surgery present a broad range of options which entail different risks and vary considerably in eco- nomic costs. Hickenbottom emphasized that "for most patients with PFO, treatment with aspirin for antiplatelet therapy would seem to provide a reasonable approach; for patients with PFO who may be at a higher risk of paradoxical embolism (underlying hypercoaguable state, recorrent embolic events), alternative options of anticoagulation, combined antiplatelet therapy or percutaneous closure could be pursued" (Anticoagulation in acute ischemic stroke - AAN Annual Meeting of San Francisco, 2004). The PICSS study ${ }^{21}$ showed no statistically significant difference in mortality or frequency of recurrent stroke between patients treated with adjusted-dose warfarin at $2 \mathrm{mg}$ or aspirin at $300 \mathrm{mg}$, both taken once daily. The results of PICSS support those reported by Mas et al. ${ }^{22}$. Despite the expectation that warfarin would be superior to aspirin in preventing recurrent stroke, no data are currently available to support this assumption. Thus, the role of these medications is limited to treating patients with a proven venous thrombus or coagulopathy.

Surgical or endovascular closure could be the best option in very young patients if we consider the risks of a lifelong anticoagulation or antiplatelet thera$\mathrm{py}^{8,23,24}$. Mechanical closure of the PFO has been proposed as the definite way to prevent recurrent paradoxical embolism. Some carefully selected patients might benefit from surgery, but currently the features that would necessitate direct operative closure are not known. With the advances in transcatheter endovascular placement of closure devices, the role of major cardiac surgery seems to be diminishing. The procedure has several advantages. It can be done on an outpatient basis using local anesthesia and usually takes less than 30 minutes. The PFO can be closed completely in approximately $95 \%$ of patients ${ }^{3}$.

Considerable uncertainty exists about the management of patients with PFO and stroke ${ }^{12,25}$. At present, no particular therapy can be recommended for asymptomatic patients with $\mathrm{PFO}^{26}$. No data prove that any medical or surgical intervention, including endovascular closure, is superior to aspirin in these patients ${ }^{22}$. Trials are needed to determine the indications and limitations of the surgical procedures ${ }^{25}$.

Our young patient had no other comorbidity except for the mitral valve prolapse. Gilon et al. ${ }^{27}$ concluded, in their case-control study, that mitral-valve prolapse is considerably less common than previously reported among young patients with stroke or transient ischemic attack and no more common than among controls. Using specific and currently accept- 
ed echocardiographic criteria, they could not demonstrate an association between the presence of mitralvalve prolapse and acute ischemic neurologic events in young people.

A 39-year-old sister of the patient had a history of a twelve-day hospitalization due to lower limb venous thrombosis. She was anticoagulated for a short period with total recovery from symptoms. On that occasion, no further investigation was carried out due to family financial problems. The possibility of family thrombophilia should be considered, in spite of the thorough investigation carried out on the reported patient.

In conclusion, interatrial septal abnormalities, including PFO, have been postulated as an additional risk factor for embolism among young ischemic stroke patients. Although its role is a matter of debate and earlier studies have suggested that PFO is an incidental finding, case studies have shown a higher prevalence of PFO in young stroke patients than in the controls. However, large studies need to be conducted to support the connection between interatrial septal abnormalities and ischemic stroke in young adults.

\section{REFERENCES}

1. Ferro JM. Cardioembolic stroke: an update. Lancet Neurol 2003;2: 177-188.

2. Falk RH. PFO or UFO? The role of a patent foramen ovale in cryptogenic stroke. Am J Journal 1991; 121:1264-1266.

3. Meier B, Lock JE. Contemporary management of patent foramen ovale. Circulation 2003;107:5-9.

4. Tobis J. The case for closing PFOs. Catheter Cardiovasc Interv 2002;55: 195-196.

5. Meissner I, Whisnant J, Khandheria BK, et al. Prevalence of potential risk factors for stroke assessed by transesophageal echocardiography and carotid ultrassonography: the SPARC Study. Mayo Clin Proc 1999; 74:862-869.

6. Lechat P, Mas JL, Lascault G et al. Prevalence of patent foramen ovale in patients with stroke. N Engl J Med 1988;318:1148-1152.

7. Hagen PT, Scholz DG, Edwards WD. Incidence and size of patent foramen ovale during the first 10 decades of life: an autopsy study of 965 normal hearts. Mayo Clin Proc 1984;59:17-20.

8. Silva MTT, Rodrigues R, Tress J, Victer R, Chamiê F. Patent foramen ovale in a cohort of young patients with cryptogenic ischemic stroke. Arq Neuropsiquiatr 2005;63:427-429.

9. Lamy C, Giannesini C, Zuber M, et al. Clinical and imaging findings in cryptogenic stroke patients with and without patent foramen ovale: the PFO-ASA Study. Stroke 2002;33:706-711.

10. Overell JR, Bone I, Lees KR. Interatrial septal abnormalities and stroke: a meta-analysis of case-control studies. Neurology 2000;55:1172-1179.

11. Berthet K, Lavergne T, Cohen A, et al. Significant association of atrial vulnerability with atrial septal abnormalities in young patients with ischemic stroke of unknown cause. Stroke 2000;31:398-403.

12. Halperin JL, Fuster V. Patent foramen ovale and recurrent stroke: another paradoxical twist. Circulation 2002;105:2580-2582.

13. Fukujima MM, Tatani SB, Aguiar AS, et al. Transesophageal echocardiography discloses unexpected cardiac sources of embolus in stroke patients aged more than 45 years. Arq Neuropsiquiatr 2005;63:941-945.

14. Mesa D, Franco M, Lezo JS, et al. Prevalence of patent foramen ovale in young patients with cryptogenic stroke. Rev Esp Cardiol 2003; 56:662668

15. Pearson AC, Labovitz AJ, Tatineni S, Gomez C. Superiority of transesophageal echocardiography in detecting cardiac source of embolism in patients with cerebral ischemia of uncertain etiology. J Am Coll Cardiol 1991;17:66-72.

16. Lee RJ, Bartakis T, Yoeh T, Grogin HR, Choi D.. Enhanced detection of intracardiac sources of cerebral emboli by tranesophageal echocardiography. Stroke 1991;22:734-739.

17. Negrão EM, Brandi IV, Nunes SV, Beraldo PSS. Alterações do septo interatrial e acidente vascular cerebral isquêmico em adultos jovens. Arq Neuropsiquiatr 2005;63:1047-1053.

18. Horton SC, Bunch TJ. Patent foramen ovale and stroke. Mayo Clin Proc 2004;79:35-41.

19. Schuchlenz HW, Weis W, Beitzke A, Stein JI, Gamillscheg A, Rehak P. Transesophageal echocardiography for quantifying size of patent foramen ovale in patients with crytogenic cerebrovascular events. Stroke 2002;33:293-296.

20. De Castro S, Cartoni D, Fiorelli M, et al. Morphological and functional characteristics of patent foramen ovale and their embolic implications. Stroke 2000;31:2407-2413.

21. Homma S, Sacco RL, Di Tullio MR, Sciacca RR, Mohr JP. PFO in Cryptogenic Stroke (PICSS) Investigators. Effect of medical treatment in stroke patients with patent foramen ovale: patent foramen ovale in Cryptogenic Stroke Study. Circulation 2002;105:2625-2631.

22. Mas JL, Arquizan C, Lamy C, et al, Patent Foramen Ovale and Atrial Septal Aneurysm Study Group. Recurrent cerebrovascular events associated with patent foramen ovale, atrial septal aneurysm or both. $\mathrm{N}$ Engl J Med 2001;345:1740-1746.

23. Naess H, Nyland HI, Thomassen L, Aarseth J, Myhr KM. Long-term outcome of cerebral infarction in young adults. Acta Neurol Scand 2004; 110:107-112.

24. Homma S, Di Tullio MR, Sacco RL, Sciacca RR, Smith C, Mohr JP. Surgical closure of patent foramen ovale in cryptogenic stroke patients. Stroke 1997;28:2376-2381.

25. Mas JL. Specifics of patent foramen ovale. Adv Neurol 2003;92:197-202.

26. Rodriguez CJ, Homma S. Patent foramen ovale and stroke. Curr Treat Options Cardiovasc Med 2003;5:233-240.

27. Gilon D, Buonanno FS, Joffe MM, et al. Lack of evidence of an association between mitral-valve prolapse and stroke in young patients. N Engl J Med 1999;341:8-13. 